\title{
Capsule Commentary on Navathe, et al., Do Changes in Post-acute Care Use at Hospitals Participating in an Accountable Care Organization Spillover to all Medicare Beneficiaries?
}

\author{
Michael L. Barnett, MD, MS $1,2,3$ \\ 'Department of Health Policy and Management, Harvard T.H. Chan School of Public Health, Boston, MA, USA; ${ }^{2}$ Division of General Internal \\ Medicine and Primary Care, Department of Medicine, Brigham and Women's Hospital, Boston, MA, USA; ${ }^{3}$ Department of Medicine, Harvard \\ Medical School, Boston, MA, USA.
}

J Gen Intern Med 33(6):943

DOI: $10.1007 / \mathrm{s} 11606-018-4431-9$

(c) Society of General Internal Medicine 2018

$\mathrm{T}_{\mathrm{a}}$ his careful analysis by Navathe and colleagues ${ }^{1}$ examines a crucial question in health care policy: how does postacute care (PAC) use respond to new payment incentives? The investigators explored this question in Medicare's accountable care organization (ACO) payment model, as implemented in the Medicare Shared Savings Program (MSSP) from 20122013. Early research has shown that the modest savings achieved so far in the MSSP have been concentrated in reduced PAC spending. ${ }^{2,3}$ However, a key methodological issue is that these analyses have focused exclusively on ACOattributed patients.

In general, only a minority of admitted Medicare patients will generally be attributed to a hospital's ACO. Therefore, it is an open question how hospitals would respond to ACO incentives affecting some patients but not others. Optimistically, ACO incentives could spur development of hospitalwide programs to improve the value of care delivery. On the other hand, hospitals could instead narrowly focus cost savings measures on their ACO patients, ignoring others.

Using a robust observational study design to control for selection bias among patients and hospitals treated in ACOs, Navathe and colleagues found no evidence that ACO participation changed the likelihood of patients' discharge to PAC vs. control hospitals. There was also little impact in length of stay for patients discharged to PAC. There were differential reductions in PAC payments to skilled nursing facilities and inpatient rehabilitation facilities, but these estimates did not reach statistical significance.
This important evidence from Navathe and colleagues supports the concept that the financial incentives in the ACO program are too weak to generate program-wide changes in care delivery. Together with evidence of modest savings among ACO-attributed patients in the $\mathrm{MSSP}^{2-4}$ these results imply that hospitals are narrowly responding to ACO incentives to largely target patients they are financially responsible for. It is probably unrealistic to expect system-wide delivery reform from payment changes that only affect small slices of hospitals' or individual providers' patients. ${ }^{5}$ Though the ACO model has promise, this study reinforces that their current implementation lacks the teeth necessary to create true reform.

Corresponding Author: Michael Barnett, MD, MS; Department of Health Policy and Management Harvard T.H. Chan School of Public Health, Boston, MA, USA (e-mail: mbarnett@hsph.harvard.edu).

\section{Compliance with ethical standards:}

Conflict of interest: The author declares that he does not have a conflict of interest.

\section{REFERENCES}

1. Navathe AS, Bain AM, Werner RM. Do changes in post-acute care use at hospitals participating in an accountable care organization spillover to all Medicare beneficiaries? J Gen Intern Med 2018 https://doi.org/10.1007/ s11606-018-4368-Z

2. McWilliams JM, Hatfield LA, Chernew ME, Landon BE, Schwartz AL. Early Performance of Accountable Care Organizations in Medicare. N Engl J Med 2016;374(24):2357-66.

3. McWilliams JM, Gilstrap LG, Stevenson DG, Chernew ME, Huskamp HA, Grabowski DC. Changes in Postacute Care in the Medicare Shared Savings Program. JAMA Intern Med 2017

4. McWilliams JM. Changes in Medicare Shared Savings Program Savings From 2013 to 2014. JAMA 2016;316(16):1711-3.

5. Landon BE. Tipping the Scale - The Norms Hypothesis and Primary Care Physician Behavior. N Engl J Med 2017;376(9):810-1. 